\title{
The use of self-induced X-ray fluorescence in gamma-ray spectroscopy of uranium ore samples
}

\author{
$\underline{\text { T. Marchais }}^{1 *}$, B. Pérot ${ }^{1}$, C. Carasco ${ }^{1}$, J-L. Ma ${ }^{1}$, P-G. Allinei ${ }^{1}$, H. Toubon ${ }^{2}$, R. Goupillou ${ }^{3}$ J. Collot ${ }^{4}$ \\ ${ }^{1}$ DEN/CAD/DTN/SMTA/LMN \\ ${ }^{2}$ ORANO Mining \\ ${ }^{3}$ SEPA/SET ORANO Mining \\ ${ }^{4}$ Laboratory of Subatomic Physic and Cosmology, Université Grenoble Alpes, CNRS/IN2P3 \\ * thomas.marchais@cea.fr
}

\begin{abstract}
Gamma logging for uranium exploration are currently based on total counting with Geiger Müller gas detectors or NaI (TI) scintillators. However, the total count rate interpretation in terms of uranium concentration may be impaired in case of roll fronts, when the radioactive equilibrium of the natural ${ }^{238} \mathrm{U}$ radioactive chain is modified by differential leaching of uranium and its daughter radioisotopes of thorium, radium, radon, etc. Indeed, in case of secular equilibrium, more than $95 \%$ of gamma rays emitted by uranium ores come from ${ }^{214} \mathrm{~Pb}$ and ${ }^{214} \mathrm{Bi}$ isotopes, which are in the back-end of ${ }^{238} \mathrm{U}$ chain. Consequently, these last might produce an intense gamma signal even when uranium is not present, or with a much smaller activity, in the ore. Therefore, gamma spectroscopy measurements of core samples are performed in surface with high-resolution hyper-pure germanium HPGe detectors to directly characterize uranium activity from the $1001 \mathrm{keV}$ gamma ray of ${ }^{234 \mathrm{~m}} \mathrm{~Pa}$, which is in the beginning of ${ }^{238} \mathrm{U}$ chain. However, due to the low intensity of this gamma ray, i.e. $0.84 \%$, acquisitions of several hours are needed. In view to characterize uranium concentration within a few minutes, we propose here a method using both the $92 \mathrm{keV}$ gamma ray of ${ }^{234} \mathrm{Th}$ and the $98.4 \mathrm{keV}$ uranium $\mathrm{X}$-ray. This last is due to uranium self-induced fluorescence caused by gamma radiations of ${ }^{214} \mathrm{~Pb}$ and ${ }^{214} \mathrm{Bi}$, which create a significant Compton scattering continuum acting as a fluorescence source and resulting in the emission of uranium fluorescence $\mathrm{X}$-rays. The comparison of the uranium activity obtained with the $92 \mathrm{keV}$ and $98.4 \mathrm{keV}$ lines allows detecting a uranium heterogeneity in the ore. Indeed, in case of uranium nugget, the $92 \mathrm{keV}$ line leads to underestimated uranium concentration due to gamma self-absorption, but on the contrary the $98.4 \mathrm{keV}$ line leads to an overestimation because of increased fluorescence. In order to test this new approach, several tens of uranium ore samples have been measured with a handheld HPGe FALCON 5000 detector.
\end{abstract}

Index Terms - Self-induced X-ray fluorescence, gamma-ray spectroscopy, germanium detector, uranium mining, MCNP6

\section{INTRODUCTION}

C urrent gamma measurements used to characterize the uranium content of ore samples are mainly based on two estimators. The first one is the total gamma count rate, which is approximately $90 \%$ due to gamma radiations of ${ }^{214} \mathrm{~Pb}$ and ${ }^{214} \mathrm{Bi}$ daughters (see further Fig. 1), in the back-end of ${ }^{238} \mathrm{U}$ chain. It allows short acquisition times but it is subject to potential imbalances in this decay chain. The second one is the $1001 \mathrm{keV}$ gamma ray of ${ }^{234 \mathrm{~m}} \mathrm{~Pa}$ daughter in the beginning of ${ }^{238} \mathrm{U}$ chain, which is therefore not subject to a potential disequilibrium of the decay chain. Moreover, the sample mineralogy has little impact on attenuation of this radiation with a relatively high energy. However, its emission intensity is very small $(0.847 \%)$ and its detection requires acquisition times of several hours, see Fig. 1. The objective of this study is to measure uranium content using more intense lines at lower energy, i.e. the $92 \mathrm{keV}$ gamma ray of ${ }^{234} \mathrm{Th}$ and ${ }^{235} \mathrm{U}$, and the $98 \mathrm{keV}$ line due to uranium self-induced fluorescence (and to a lesser extend to a ${ }^{234 \mathrm{~m}} \mathrm{~Pa}$ gamma ray). This study is performed with samples of crushed ore filling a PVC holder. The gamma spectra are measured with a Falcon 5000 [1] handheld spectrometer from Mirion-Canberra, equipped with a HPGe planar detector (BEGE 2830 model). The method is studied by MCNP6 Monte Carlo calculation by the Nuclear Measurement Laboratory of CEA, DEN, Cadarache, and validated with experimental data obtained by ORANO Mining during a measurement campaign intended to characterize uranium content and imbalance of the samples [2].

The two rays at $92 \mathrm{keV}$ and $98 \mathrm{keV}$ are systematically present with a high intensity on uranium ore spectra (see example of a small concentration sample in Fig. 1), which makes it possible to envisage a significant measurement time reduction with respect to $1001 \mathrm{keV}$ line.

\section{ANALYSIS OF THE GAMMA SPECTRUM}

\section{A. Typical gamma spectrum of a uranium ore sample}

Fig. 1 shows a typical HPGe high-resolution gamma spectrum of a real ore sample with a 419 ppm uranium concentration. The experimental setup is described further in Section II. In this section, we develop the theoretical formulae used to determine the uranium concentration from the net area of $1001 \mathrm{keV}$, $92 \mathrm{keV}$ and $98 \mathrm{keV}$ peaks, respectively. The concentration obtained with the $1001 \mathrm{keV}$ gamma ray is considered in this work as the reference because it is less sensitive to attenuation effects compared to the two other low-energy radiations. 


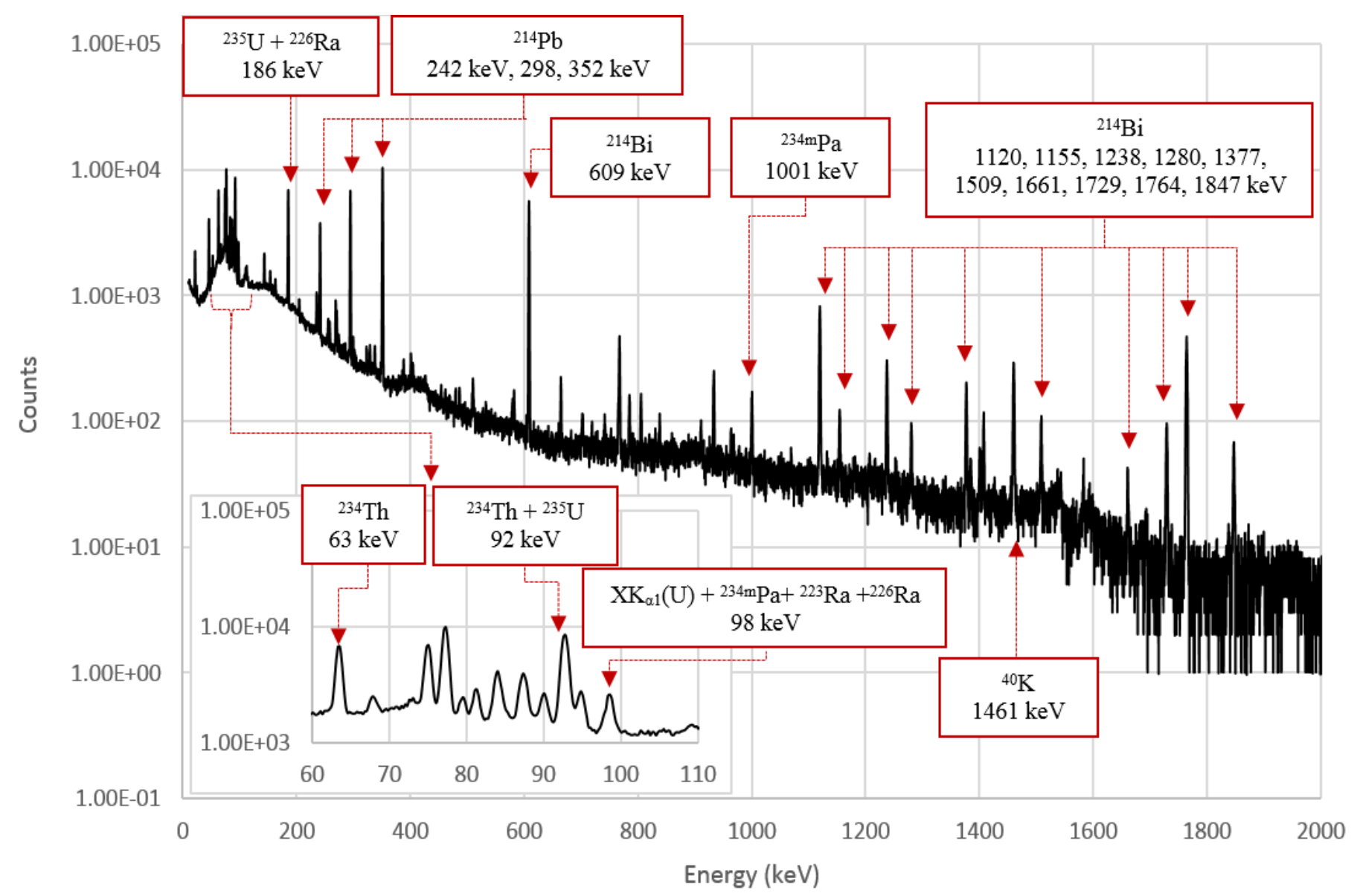

Fig. 1. Experimental spectrum of a $479 \mathrm{~g}$ ore sample with an uranium concentration of $419 \mathrm{ppm}_{\mathrm{U}}$ and a density of $1.46 \mathrm{~g} . \mathrm{cm}^{-3}$ with for 7503 seconds of acquisition

\section{B. Radioactive gamma emission at $1001 \mathrm{keV}$}

Equation (1) allows converting the net area of the $1001 \mathrm{keV}$ peak into uranium mass concentration in ppm (i.e. in $\mathrm{mg}$ of uranium per $\mathrm{kg}$ of ore, dimensionless unit). This equation has been already used and validated during a measurement campaign in Bessines (France) calibration facility [3].

Where :

$$
C m_{u}(1001 \mathrm{keV})=\frac{S_{n}(1001 \mathrm{keV})}{T c \times M_{s} \times C E_{1001}}(1)
$$

$$
C E_{1001}=\frac{E f f_{1001 \mathrm{keV}} \times I_{1001 \mathrm{keV}}\left({ }_{91}^{234 m} \mathrm{~Pa}\right) \times \mathrm{Na} \times \ln (2)}{(1+\eta) \times 10^{6} \times M\left({ }_{92}^{238} \mathrm{U}\right) \times T_{\frac{1}{2}}\left({ }_{92}^{238} \mathrm{U}\right)}
$$

With:

- $C m_{u}(1001 \mathrm{keV})$ : uranium mass concentration (in ppm) of the sample calculated thanks to the gamma ray at $1001 \mathrm{keV}$,

- $S_{n}(1001 \mathrm{keV})$ : net area of the peak at $1001 \mathrm{keV}$ measured on the gamma spectrum after subtraction of the Compton continuum under the peak (number of counts, dimensionless number),

- Tc: acquisition "live time" (i.e. real time corrected for dead time) of the gamma spectrum (s),

- $M_{s}$ : mass of the sample $(\mathrm{g})$,

- Eff $f_{1001 \mathrm{keV}}$ : detection efficiency calculated with MCNP [4] (number of count in the full-energy peak at $1001 \mathrm{keV}$ per photon of $1001 \mathrm{keV}$ emitted in the sample),
- $I_{1001 \mathrm{keV}}\left({ }_{91}^{234 \mathrm{~Pa}}\right)$ : intensity of the $1001 \mathrm{keV}$ gamma ray of ${ }^{234 \mathrm{mPa}}$ (number of gamma radiation emitted per disintegration: $0.847 \%$ [5]) in the ${ }^{238} \mathrm{U}$ decay chain,

- Na: Avogadro constant $\left(6,023 \cdot 10^{23}\right.$ atoms per mole, dimensionless number),

- $\eta$ : mass fraction of ${ }^{235} \mathrm{U}$ in natural uranium $(0.72 \%)$,

- $M\left({ }_{92}^{238} U\right)$ : molar mass of ${ }^{238} \mathrm{U}(\mathrm{g})$,

- $T_{\frac{1}{2}}\left({ }_{92}^{238} \mathrm{U}\right):{ }^{238} \mathrm{U}$ radioactive period $\left(4.510^{9} \mathrm{a} \equiv 141.010^{15} \mathrm{~s}\right)$.

C. Radioactive gamma and X-ray emissions at $92 \mathrm{keV}$

The "92 keV" peak is already used in ORANO Mining laboratories for fast uranium characterization. It is composed of close-in-energy lines mainly due to ${ }^{235} \mathrm{U}$ and ${ }^{234} \mathrm{Th}$ :

(1) the $\alpha$-decay of ${ }^{235} \mathrm{U}$ towards ${ }^{231} \mathrm{Th}$ is followed by the emission of a thorium X-ray at $93.35 \mathrm{keV}$, after internal conversion of the excited ${ }^{231} \mathrm{Th}$ daughter. This X-ray contributes to the signal at $92 \mathrm{keV}$ due to the finite resolution of the detector, with a tabulated emission intensity $I_{93 \mathrm{keV}}\left({ }_{92}^{235} \mathrm{U}\right)=5.75 \%$ [5],

(2) ${ }^{234} \mathrm{Th}$ (in the beginning of the ${ }^{238} \mathrm{U}$ decay chain) emits two gamma rays at $92.38 \mathrm{keV}$ and $92.80 \mathrm{keV}$ following its $\beta^{-}$ radioactive decay into ${ }^{234} \mathrm{~Pa}$. We use here the total intensity $I_{92 \mathrm{keV}}\left({ }_{90}^{234} \mathrm{Th}\right)=4.33 \%[5]$,

$\mathrm{As}^{235} \mathrm{U}$ and ${ }^{234} \mathrm{Th}$ are located at the top of the uranium decay chains, the net area of the $92 \mathrm{keV}$ peak is not subject to potential imbalances and correctly reflects the uranium concentration. 
Equation (2) allows converting the net area of the $92 \mathrm{keV}$ peak into uranium mass concentration.

$$
C m_{U}(92 \mathrm{keV})=\frac{s_{n}(92 \mathrm{keV})}{T c \times M_{e c h} \times C E_{92}}(2)
$$

Where:

$$
\begin{aligned}
& \text { - } C E_{92}=C E_{90}^{234} \mathrm{Th}+C E_{235}{ }_{92} u \\
& \text { - } C E_{90}^{234}{ }_{90} T h=\frac{E f f_{92 k e V} \times I_{92 \mathrm{keV}}\left({ }_{90}^{234} \mathrm{Th}\right) \times \ln (2) \times \mathrm{Na}}{1.0072 \times 10^{6} \times M\left({ }_{92}^{238} \mathrm{U}\right) \times T_{\frac{1}{2}}\left({ }_{92}^{238} \mathrm{U}\right)} \\
& -C E_{235} u=\frac{\frac{A\left({ }_{92}^{235} \mathrm{U}\right)}{A\left({ }_{92}^{238} \mathrm{U}\right)} \times E f f_{93 \mathrm{keV}} \times I_{93 \mathrm{keV}}\left({ }_{92}^{235} \mathrm{U}\right) \times \ln (2) \times \mathrm{Na}}{(1+\eta) \times 10^{6} \times M\left({ }_{92}^{238} \mathrm{U}\right) \times T_{\frac{1}{2}}\left({ }_{92}^{238} \mathrm{U}\right)}
\end{aligned}
$$

With:

- $C m_{U}(92 \mathrm{keV})$ : uranium mass concentration in ppm of sample calculated thanks to the $92 \mathrm{keV}$ ray,

- Tc: acquisition "live time" (i.e. real time corrected for dead time) of the gamma spectrum (s),

- $M_{s}$ : mass of the sample $(\mathrm{g})$,

- $S_{n}(92 \mathrm{keV}$ ): net area of the peak at $92 \mathrm{keV}$ (number of counts, dimensionless number),

- $I_{92 \mathrm{keV}}\left({ }_{90}^{234} \mathrm{Th}\right)$ : total intensity of the two $92 \mathrm{keV}$ close peaks of ${ }^{234} \mathrm{Th}\left(4.33 \%\right.$ [5]), in the ${ }^{238} \mathrm{U}$ decay chain,

- $E f f_{92 \mathrm{keV}}, E f f_{93 \mathrm{keV}}$ : detection efficiency calculated with MCNP (number of count in the full-energy peak at $92 \mathrm{keV}$ or $93 \mathrm{keV}$, respectively per photon of $92 \mathrm{keV}$ or $93 \mathrm{keV}$ emitted in the sample),

- $\frac{A\left({ }_{92}^{235} U\right)}{A\left({ }_{92}^{238} U\right)}$ : activity ratio of ${ }^{235} \mathrm{U}$ and ${ }^{238} \mathrm{U}(0.046$ in case of natural enrichment, i.e. $0.72 \%$ of $\left.{ }^{235} \mathrm{U}\right)$,

- $I_{93 \mathrm{keV}}\left({ }_{92}^{235} \mathrm{U}\right)$ : emission intensity at $93 \mathrm{keV}$ of ${ }^{235} \mathrm{U}$ (5.75\% [5]).

\section{Radioactive emission at $98 \mathrm{keV}$}

The $98 \mathrm{keV}$ peak is dominated by four contributions:

(1) the $\mathrm{X}-\mathrm{K}_{\alpha 1}$ fluorescence line of uranium at $98.44 \mathrm{keV}$. The net area of this peak does not follow linearly uranium concentration, contrary to the above radioactive-decay emissions, but it rises in a quadratic way because of the combined increase of fluorescence source intensity (gamma emitters of the uranium chain) and uranium quantity itself (which undergoes fluorescence).

2 the same $98.44 \mathrm{keV}$ X-ray but emitted after the $\beta$ disintegration of ${ }^{234 \mathrm{~m}} \mathrm{~Pa}$ (at the beginning of the ${ }^{238} \mathrm{U}$ decay chain) into ${ }^{234} \mathrm{U}$, followed by internal conversion. The tabulated emission intensity is $I_{98 \mathrm{keV}}\left({ }_{91}^{234 \mathrm{~Pa}} \mathrm{P}\right)=0.316 \%$,

3 two close $97.53 \mathrm{keV}$ and $97.85 \mathrm{keV}$ X-rays linked to ${ }^{223} \mathrm{Ra}$ $\left({ }^{235} \mathrm{U}\right.$ decay chain) $\alpha$-decay into ${ }^{219} \mathrm{Rn}$, followed by internal conversion of the excited daughter ${ }^{219} \mathrm{Rn}$. The tabulated total intensity for these two X-rays is $I_{92 \mathrm{keV}}\left({ }_{88}^{223} R a\right)=2.72 \%$ [5], 4 the same $97.53 \mathrm{keV}$ and $97.85 \mathrm{keV} X$-rays but linked to ${ }^{226} \mathrm{Ra}$ ( ${ }^{238} \mathrm{U}$ decay chain) $\alpha$-decay towards ${ }^{222} \mathrm{Rn}$, again followed by internal conversion. The tabulated total intensity is here $I_{92 \mathrm{keV}}\left({ }_{88}^{226} R a\right)=0.036 \%[5]$.
Concerning the first contribution, each gamma ray emitted by the uranium decay chain can cause the fluorescence of uranium after undergoing Compton scattering and photoelectric absorption in the sample. In order to quantify the ability of a photon of energy $\mathrm{E}$ to induce uranium fluorescence, the $\eta_{\text {fluo }}(E)$ yield defined in equation (3) is calculated by MCNP (in $\mathrm{g}^{-1}$ units). This fluorescence yield is specific to the geometry of the sample: uranium content, filling height, density, mineralogy.

$$
\eta_{\text {fluo }}(E)=\frac{s_{n}\left(X K_{\alpha 1}\right)}{S_{n}(E) \times C m_{U} \times M_{S}}(3)
$$

With:

- $S_{n}\left(X K_{\alpha 1}\right)$ : net area of the $\mathrm{XK}_{\alpha 1}$ fluorescence line of uranium at $98.4 \mathrm{keV}$ (number of counts, dimensionless number),

- $S_{n}(E)$ : net area, on the MCNP spectrum, at the simulated energy $\mathrm{E}$ (number of counts, dimensionless number),

- $C m_{U}$ : uranium mass concentration (in ppm) in the MCNP model of the sample,

- $M_{S}$ : mass of the sample (g).

A typical fluorescence yield calculation with a mono-energy $200 \mathrm{keV}$ photon is shown in Fig. 2.

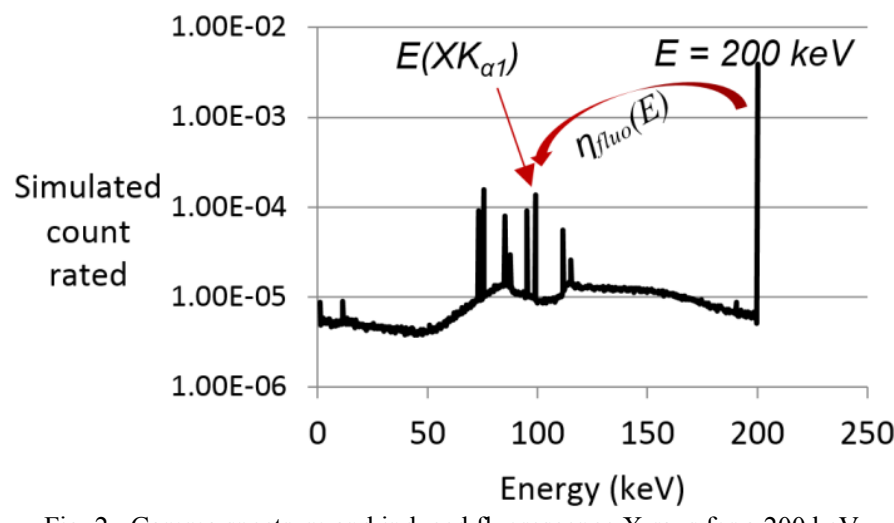

Fig. 2. Gamma spectrum and induced fluorescence X-rays for a $200 \mathrm{keV}$ mono-energy photon source.

The fluorescence yield and the three radioactive decay emissions listed above allow us to convert the net area of the $98 \mathrm{keV}$ peak into a uranium mass concentration using equation (4). It is important to notice that, in order to limit the number of simulations, only the six more intense gamma rays were taken into account to calculate the fluorescence yield: $185 \mathrm{keV}$ $\left({ }^{214} \mathrm{~Pb}\right), 242 \mathrm{keV}\left({ }^{214} \mathrm{~Pb}\right), 298 \mathrm{keV}\left({ }^{214} \mathrm{~Pb}\right), 352 \mathrm{keV}\left({ }^{214} \mathrm{~Pb}\right)$, $609 \mathrm{keV}\left({ }^{214} \mathrm{Bi}\right)$ and $1120 \mathrm{keV}\left({ }^{214} \mathrm{Bi}\right)$. As they represent $78 \%$ of the total fluorescence signal, a correction factor $\mathrm{F}$ equal to 0.78 is used in equation (4).

$$
C m_{U}(98 \mathrm{keV})=\frac{s_{n}(98 \mathrm{keV})}{T c \times M_{S} \times C E_{98}}(4)
$$

Where:

$$
\begin{aligned}
& -C E_{98}=C E_{226}{ }_{88} R a+C E_{223 R a}+C E_{88}^{234 m_{91} P a}+\frac{\sum_{E_{\gamma}}\left[\mathrm{n}_{\text {fluo }}\left(E_{\gamma} d, h\right) \times S_{n}\left(E_{\gamma}\right)\right]}{T c \times \mathrm{F}} \\
& -C E_{226} R a=\frac{\frac{A\left({ }_{88}^{226} R a\right)}{A\left({ }_{92}^{238} \mathrm{U}\right)} \times E f f_{98 \mathrm{keV}} \times I_{98 \mathrm{keV}}\left({ }_{88}^{226} R a\right) \times \ln (2) \times \mathrm{N} a}{(1+\eta) \times 10^{6} \times M\left({ }_{92}^{238} \mathrm{U}\right) \times T_{\frac{1}{2}}\left({ }_{92}^{238} \mathrm{U}\right)}
\end{aligned}
$$




$$
\begin{aligned}
& -C E_{223}^{223}=\frac{\frac{A\left({ }_{88}^{223} \mathrm{Ra}\right)}{A\left({ }_{92}^{38} \mathrm{U}\right)} \times E f f_{98 \mathrm{keV}} \times \ln (2) \times \mathrm{Na} \times I_{98 \mathrm{keV}}\left({ }_{88}^{223} \mathrm{Ra}\right)}{(1+\eta) \times 10^{6} \times M\left({ }_{92}^{238} \mathrm{U}\right) \times T_{\frac{1}{2}}\left({ }_{92}^{238} \mathrm{U}\right)} \\
& -C E_{234 m_{91} \mathrm{~Pa}}^{2}=\frac{E f f_{98 \mathrm{keV}} \times I_{98 \mathrm{keV}}\left({ }^{234 m}{ }_{91} \mathrm{~Pa}\right) \times \ln (2) \times \mathrm{Na}}{(1+\eta) \times 10^{6} \times M\left({ }_{92}^{238} \mathrm{U}\right) \times T_{\frac{1}{2}}\left({ }_{88}^{238} \mathrm{U}\right)}
\end{aligned}
$$

With:

- $\mathrm{Cm}_{U}(98 \mathrm{keV})$ : uranium mass concentration (in ppm) of the sample calculated thanks to the $98 \mathrm{keV}$ ray,

- Tc: acquisition "live time" (i.e. real time corrected for dead time) of the gamma spectrum (s),

- $M_{s}$ : mass of the sample $(\mathrm{g})$,

- $S_{n}(98 \mathrm{keV})$ : net area of the peak at $98 \mathrm{keV}$ (number of counts, dimensionless number),

- Eff $f_{98 \mathrm{keV}}$ : detection efficiency calculated with MCNP (number of count in the full-energy peak at $98 \mathrm{keV}$ per photon of $98 \mathrm{keV}$ emitted in the sample),

- I $I_{98 \mathrm{keV}}\left({ }_{88}^{223} \mathrm{Ra}\right)$ : emission intensity at $98 \mathrm{keV}$ of ${ }^{223} \mathrm{Ra}$ $(2.72 \%[5])$,

- $I_{92 \mathrm{keV}}\left({ }_{88}^{226} \mathrm{Ra}\right)$ : emission intensity at $98 \mathrm{keV}$ of ${ }^{226} \mathrm{Ra}$ $(0.0351 \%$ [5]),

- $I_{92 \mathrm{keV}}\left({ }_{91}^{234 \mathrm{~m}} \mathrm{~Pa}\right)$ : emission intensity at $98 \mathrm{keV}$ of ${ }^{234 \mathrm{~m}} \mathrm{~Pa}$ $(0.316 \%[5])$,

- $E_{\gamma}=[185,242,295,352,609,1120 \mathrm{keV}]$, energy of the 6 gamma rays selected to calculate the fluorescence yield,

- $\eta_{\text {fluo }}(E, d, h)$ : fluorescence yield (in $\left.\mathrm{g}^{-1}\right)$ as a function of gamma energy, sample density and filling height,

- $\frac{A\left({ }_{88}^{223} R a\right)}{A\left({ }_{92}^{238} U\right)}$ : activity ratio between ${ }^{223} \mathrm{Ra}$ and ${ }^{238} \mathrm{U}(0.046$ in the case of natural enrichment in $\left.{ }^{235} \mathrm{U}\right)$,
- F: correction factor to take into account the limited number the lack of gamma rays modeled in the fluorescence source (here $\mathrm{F}=0.78$ ).

\section{EXPERIMENTAL QUALIFICATION}

In order to validate the new approach described above, we use 76 gamma spectra of uranium ore samples recorded by ORANO Mining (such as the spectrum of Fig. 1) to study radioactive disequilibrium in Dulann Uul and Zoovch Ovoo deposits, Mongolia [2]. The samples have different densities and filling heights. The uranium ore was coarsely crushed with a hammer and placed in a flask, as shown in Fig. 3. The crushed samples have an average density of $1.4 \mathrm{~g} . \mathrm{cm}^{-3}$. The average filling height is $6 \mathrm{~cm}$ and the sample holder diameter is $11 \mathrm{~cm}$. The sample is placed on PVC shims of variable height to ensure the contact between the detector cover and the ore sample. In addition, a copper shielding was used to absorb fluorescence X-rays of the lead shielding (Fig. 3). The BEGE 2830 planar HPGe crystal of the FALCON 5000 handheld detector (from MIRIONCANBERRA) has a $60 \mathrm{~mm}$ diameter and a $30 \mathrm{~mm}$ length. In order to calculate the fluorescence yield, the measurement geometry was modeled with MCNP6 Monte-Carlo transport code [4], see Fig. 3.

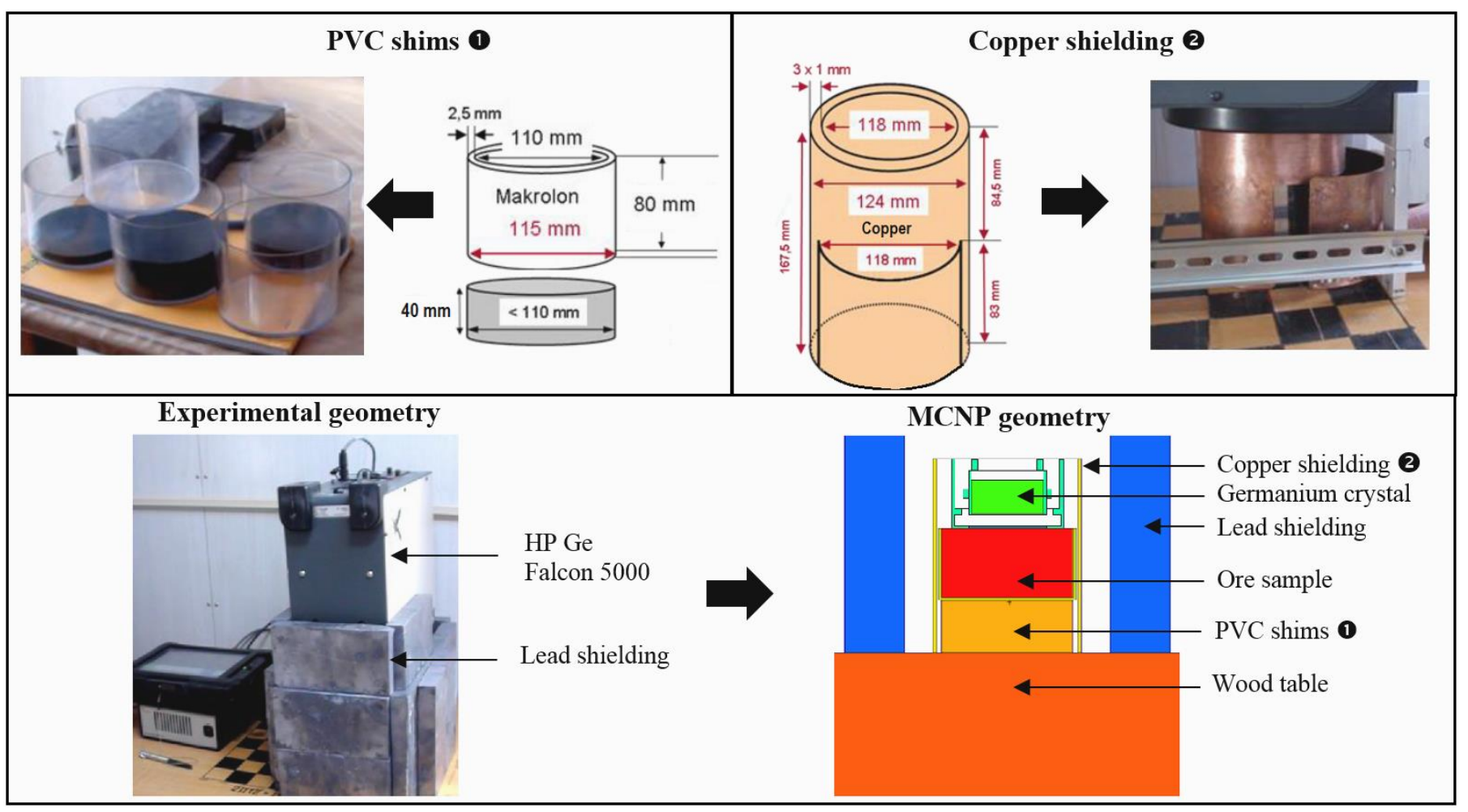

Fig. 3. Experimental and simulated geometry. On the upper left side, the PVC shims. On the upper right side, the copper shielding. At the bottom, the experimental geometry and the MCNP geometry. 
Efficiencies at $92 \mathrm{keV}, 98 \mathrm{keV}$ and $1001 \mathrm{keV}$ are those calculated with ISOCS software [6] for a typical FALCON 5000 geometry. The uncertainty associated to calculated efficiencies is $10 \%$ for $92 \mathrm{keV}$ and $98 \mathrm{keV}$ peaks and $5 \%$ for $1001 \mathrm{keV}$ peak.

The following graph represents the $\mathrm{Cm}_{U}(92 \mathrm{keV})$ and $\mathrm{Cm}_{U}(98 \mathrm{keV})$ concentrations calculated with the net area of the $92 \mathrm{keV}$ and $98 \mathrm{keV}$ peaks, respectively, as a function of the concentration calculated with the $1001 \mathrm{keV}$ peak, which is considered as the reference.
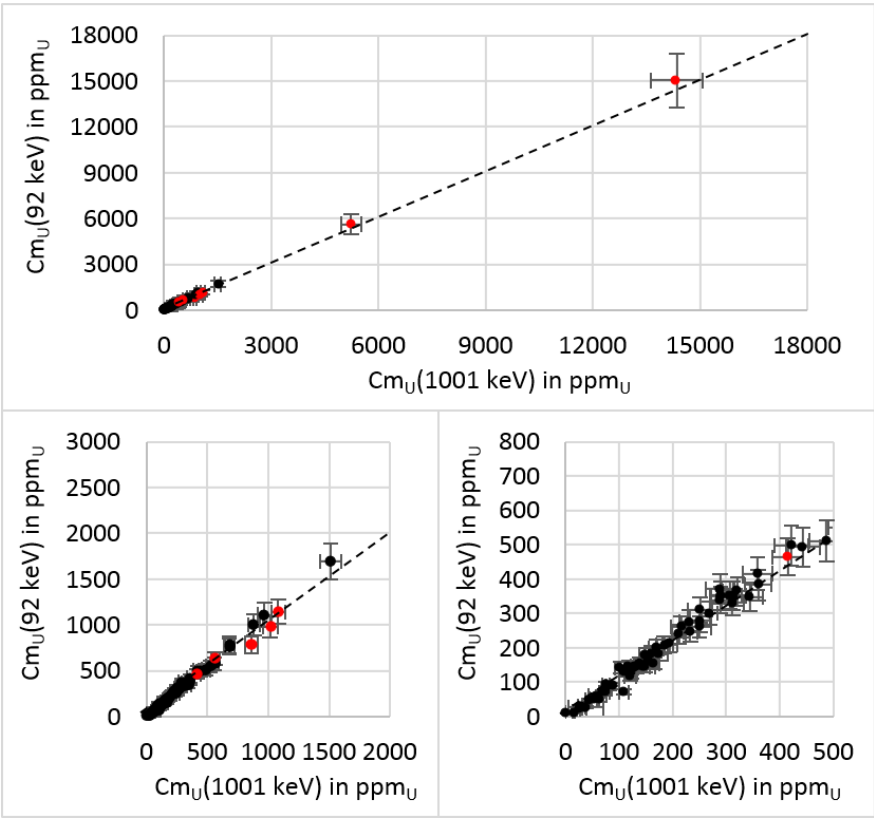

Fig. 4. Uranium content $\mathrm{Cm}_{U}(92 \mathrm{keV})$ as a function of $\mathrm{Cm}_{U}(1001 \mathrm{keV})$.

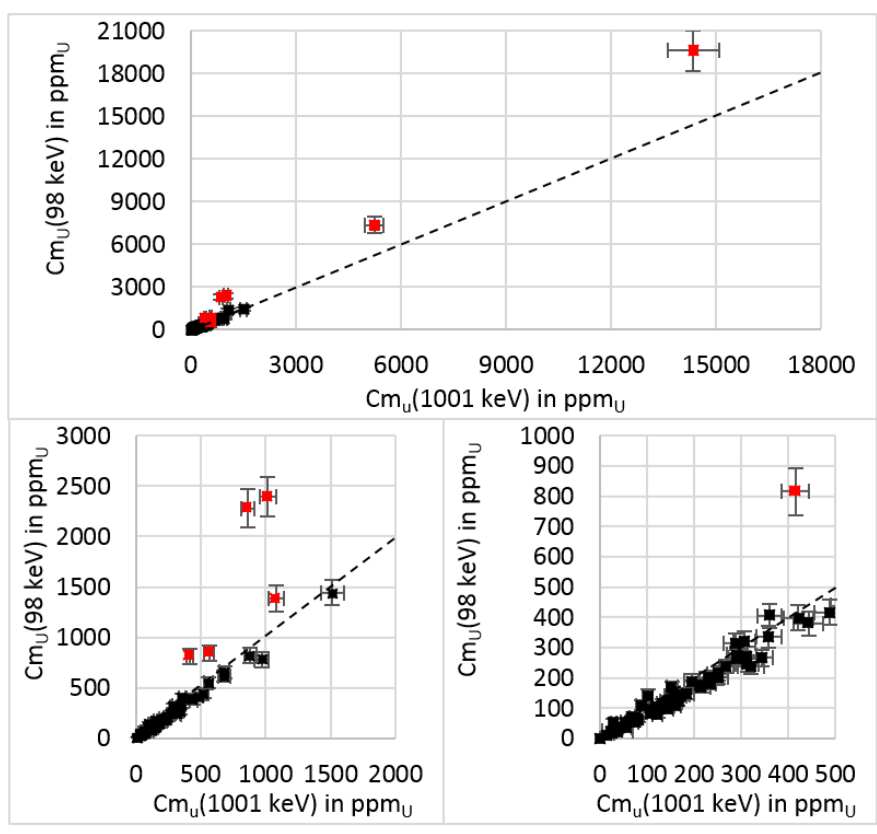

Fig. 5. Uranium content $\mathrm{Cm}_{U}(98 \mathrm{keV})$ as a function of $C m_{U}(1001 \mathrm{keV})$.

The uncertainty calculated for each sample (considered as homogeneous) includes:
- detector calibration and detection efficiency calculation by ISOCS [6],

- the statistical uncertainty on the net area of the $1001 \mathrm{keV}, 92 \mathrm{keV}$ and $98 \mathrm{keV}$ peaks,

- the relative uncertainties on the intensities of the gamma or X-rays of interest are given in the nuclear databases [5]: $0.94 \%$ for the $1001 \mathrm{keV}$ gamma ray; for the $92 \mathrm{keV}$ peak it is $6.21 \%$ for the ${ }^{234} \mathrm{Th}$ contribution and $1.91 \%$ for ${ }^{235} \mathrm{U}$ part; for the $98 \mathrm{keV}$ line, it is $1.26 \%$ for ${ }^{234 \mathrm{~m}} \mathrm{~Pa}, 2.85 \%$ for ${ }^{226} \mathrm{Ra}$, and $2.57 \%$ for ${ }^{223} \mathrm{Ra}$,

- the relative uncertainty on the fluorescence yield simulated for the calculation of $\mathrm{Cm}_{U}(98 \mathrm{keV})$ is estimated to be around $20 \%$ for the six modeled gamma emissions,

- the relative uncertainty on the $F=0.78$ correction factor (for the non-modeled gamma rays inducing about $22 \%$ of the fluorescence) is estimated to be $5 \%$ based on several simulations with different samples.

An average relative uncertainty of $10.34 \%$ is thus calculated for $\mathrm{Cm}_{U}(1001 \mathrm{keV}), 11.69 \%$ for $\mathrm{Cm}_{U}(92 \mathrm{keV})$ and $12.85 \%$ for $\mathrm{Cm}_{U}(98 \mathrm{keV})$. The uncertainty on $\mathrm{Cm}_{U}(1001 \mathrm{keV})$ is mainly due to the poor counting statistics, leading to large uncertainties in both the Gaussian adjustment of the gamma ray (broadened by the detector resolution) and in the estimation of the Compton continuum under the peak. Concerning $\mathrm{Cm}_{U}(92 \mathrm{keV})$ and $\mathrm{Cm}_{U}(98 \mathrm{keV})$ the relative uncertainty on the efficiency calculated with ISOCS software dominates $(10 \%)$. It could be reduced by using a MCNP refined detector model based on a fine geometrical characterization with collimated calibration sources, which will be reported in a future article. For most of the 76 samples, $\mathrm{Cm}_{U}(92 \mathrm{keV})$ and $C m_{U}(98 \mathrm{keV})$ are consistent with the reference $\mathrm{Cm}_{U}(1001 \mathrm{keV})$, but for seven samples (in red on Fig. 4 and Fig. 5), discrepancies are observed that might be due to heterogeneities. Indeed, for all these samples, we observe the following inequality:

$$
C m_{U}(98 \mathrm{keV})>C m_{U}(1001 \mathrm{keV}) \geq C m_{U}(92 \mathrm{keV})
$$

As explained above, in case of uranium nuggets in the sample, $\mathrm{X}$ and gamma emissions following radioactive decays are more self-absorbed than with a uniform distribution, while on the contrary, X-ray fluorescence is enhanced. This phenomenon was demonstrated by simulating with MCNP a uranium nugget of $0.343 \mathrm{~g}_{\mathrm{U}}$ in a homogeneous matrix of uranium of $0.455 \mathrm{~g}_{\mathrm{U}}$. This simulation, equivalent of a homogeneous sample of 1000 ppm $_{U}$, gives $C m_{U}(92 \mathrm{keV})=690 \mathrm{ppm}_{\mathrm{U}}$ and $\mathrm{Cm}_{U}(98 \mathrm{keV})=3645 \mathrm{ppm}_{\mathrm{U}}$.

Beyond detection of possible heterogeneities, the advantage of the method is to reduce measurement time. The gain in measurement time was calculated for each sample by comparing the statistical uncertainty of the $1001 \mathrm{keV}$ with that of $92 \mathrm{keV}$ and $98 \mathrm{keV}$ peaks, taking in account the estimation and subtraction of the Compton continuum under the peaks. Than the gain in measurement time is estimated with the aim to have the same relative uncertainty in the 92 and $98 \mathrm{keV}$ lines, during a short acquisition, as in the $1001 \mathrm{keV}$ line during the long acquisition. In other words, based on Poisson law, the ratio of the $1001 \mathrm{keV}$ relative uncertainty to that of 92 or $98 \mathrm{keV}$ lines is squared to be converted in time gain. The average gain 
is 65 for $\mathrm{Cm}_{U}(92 \mathrm{keV})$ and 2 for $\mathrm{Cm}_{U}(98 \mathrm{keV})$, but they vary a lot for each sample depending of many factors such as geometry, uranium content and possible radioactive disequilibrium in the uranium chain. For instance, no gain is observed for $\mathrm{Cm}_{U}(98 \mathrm{keV})$ for very small uranium contents (namely less than 200 ppm $_{U}$ ) because self-fluorescence if too weak. On the other hand, for large uranium contents, the gain for $\mathrm{Cm}_{U}(98 \mathrm{keV})$ increases quickly because, as explained above, the intensity of fluorescence $\mathrm{X}$-ray rises with the square of uranium concentration. For instance, the gain in measurement time for the highest uranium content sample $(14,000 \mathrm{ppm})$ is about 8 for $\mathrm{Cm}_{\mathrm{U}}(98 \mathrm{keV})$.

The gain for $\mathrm{Cm} U(92 \mathrm{keV})$ fluctuates from one sample to another, but it is little dependent on uranium concentration in this range. In addition, if sample homogeneity is guaranteed (e.g. thanks to fine crushing), the time gain is a factor 70 by using the $92 \mathrm{keV}$ line only, as heterogeneity detection with the $98 \mathrm{keV}$ peak is no more necessary.

\section{CONCLUSION AND PROSPECTS}

In this work, we have shown the possibility to measure the uranium concentration of uranium ore samples by gamma-ray spectroscopy using the $92 \mathrm{keV}$ and $98 \mathrm{keV}$ lines, which lead to a large measurement time gain (minutes vs. hours) compared to the reference $1001 \mathrm{keV}$ peak. The total relative uncertainty on $\mathrm{Cm}_{U}(92 \mathrm{keV})$ and $\mathrm{Cm}_{U}(98 \mathrm{keV})$ mass concentrations measured in a short acquisition remains lower than $13 \%$, while it was about $10 \%$ for the long measurement of $\mathrm{Cm}_{U}(1001 \mathrm{keV})$.

In addition, a difference in the uranium concentrations assessed with the 92 and $98 \mathrm{keV}$ peaks, respectively, alerts the operator of a possible heterogeneity of the sample.

In next studies, the geometric MCNP model of the Falcon 5000 detector will be optimized to reduce the uncertainty on $\mathrm{Cm}_{U}(92 \mathrm{keV})$ and $\mathrm{Cm}_{U}(98 \mathrm{keV})$, which is so far dominated by modeling uncertainty. This detector is equipped with a planar HPGe crystal, which will be finely characterized with a multi-energy highly collimated ${ }^{152} \mathrm{Eu}$ gamma source. This narrow photon beam will allow precisely estimating the dead layers vs. active area of the germanium crystal [3].

We will also measure 38 additional ore samples provided by ORANO Mining, on a wider range of uranium concentrations, to fully qualify the method in the Nuclear Measurement Laboratory of CEA, DEN, Cadarache.

In parallel, we also study a low-resolution spectroscopy approach with easy-to-use room temperature $\mathrm{NaI}(\mathrm{Tl})$ or $\mathrm{LaBr}_{3}(\mathrm{Ce})$ detectors, reducing again measurement time, and system cost as well.

\section{REFERENCES}

[1] "Falcon 5000 Portable HPGe-Based Radionuclide Identifier." [Online]. Available: https:/www.mirion.com/products/falcon-portable-hpgebased-radionuclide-identifier. [Accessed: 22-Jan-2019].

[2] T. Boulesteix et al., "Ilmenites and their alteration products, sinkholes for uranium and radium in roll-front deposits after the example of South Tortkuduk (Kazakhstan)," vol. To be published.
[3] T. Marchais et al., "Detailed MCNP Simulations of Gamma-Ray Spectroscopy Measurements With Calibration Blocks for Uranium Mining Applications," IEEE Trans. Nucl. Sci., vol. 65, no. 9, pp. 2533-2538, Sep. 2018.

[4] "MCNP6TM, User's manual - Version 1.0 - LA-CP-1300634, Rev. 0 - May 2013 - Denise B. Pelowitz, editor." Los Alamos National Laboratory.

[5] "NUCLÉIDE-LARA on the web (2018)." [Online]. Available: http://www.nucleide.org/Laraweb/index.php. [Accessed: 22-Jan-2019].

[6] MIRION Technologies, "ISOCS- Model S573 ISOCS, Calibration Software." Apr-2013. 